E3S Web of Conferences 1, 00001 (2013)

DOI: $10.1051 / \mathrm{e} 3$ sconf/20130100001

(C) Owned by the authors, published by EDP Sciences, 2013

\title{
Message from the Chair
}

The $16^{\text {th }}$ International Conference on Heavy Metals in the Environment (ICHMET 2012) was held in Rome, Italy, from the $23^{\text {st }}$ to the $27^{\text {th }}$ of September, 2012. ICHMET 2012 offered its participants an opportunity to gather with scientists from all over the world. For the past 30 years, ICHMET conferences have offered participants a venue for sharing cutting-edge ideas and up-to-date research across a number of disciplines. To create this multidisciplinary exchange ICHMET 2012 did not focus on a specific metal or medium, but instead brought together national and international organizations, environmental policy experts, and renowned scientists working in a number of different fields of expertise.

For four days participants gathered together to discuss major advances in our knowledge on emission sources, transport processes, remediation techniques, and environmental policy related to heavy metals. With over three hundred participants from over fifty different countries, ICHMET 2012 featured a number of interesting and notable sessions. Special attention was paid to emerging issues related to sources and impact on human health.

The successful organization of ICHMET 2012 required the hard work of many. The International Programme Committee met and reviewed all of the extended abstracts that were submitted, and the Local Planning Committee worked closely with the Conference Secretariat to ensure all of the technical and organizational elements of the conference proceeded as planned. The employees of the CNR-IIA also worked diligently to ensure that ICHMET 2012 would be organized and pleasant for all involved. We wish to express our gratitude to all who helped make these events both successful and memorable.

In addition, we would like to offer another congratulations to Dr. Jozef Pacyna and Dr. Jerome Nriagu, who each received ICHMET's top honor, the Lifetime Achievement Award. We offer our most profound gratitude to Dr. Pacyna and Dr. Nriagu, for their years of hard work in advancing our collective understanding of heavy metals and their impacts upon the environment. We would also like to extend our thanks to Stefano Nativi, Oleg Pokrovsky, and Noelle Selin, who each organized short courses held in conjunction with the conference.

And finally, we would like to extend our gratitude to all ICHMET 2012 participants. We hope that you found the ICHMET 2012 conference to be both scientifically valuable and intellectually exciting. We also hope that you had a chance to enjoy some of the architectural, cultural, and culinary pleasures that Rome, the eternal city, has to offer. A special thank you to all participants who presented new research at the conference, and to those who overcame bureuacratic difficulties to travel to Italy from afar. We look forward to seeing you at the next ICHMET conference in Guyang, China in 2014.

Sincerely,

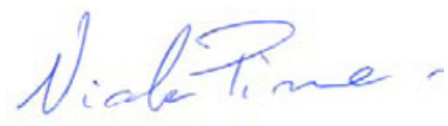

Dr. Nicola Pirrone

ICHMET 2012 Conference Chair 